\title{
Sobre técnicas e tecnologia: uma perspectiva feminista dos estudos de artefatos líticos
}

Danusa Vieira*

VIEIRA, D. Sobre técnicas e tecnologia: uma perspectiva feminista dos estudos de artefatos líticos. R. Museu Arq. Etn., vol: 36 95-108, 2021.

Resumo: Reflexões teóricas substanciais foram feitas sobre a tecnologia enquanto meio de ação no mundo físico, social e culturalmente constituído, incluindo considerações que relevam do aspecto material da produção social das técnicas, dentre outras, as invenções que são consideradas cruciais para a evolução da humanidade. Artefatos de pedra lascada se encontram nessa categoria fundamental, tendo se constituído enquanto produção técnica intencional especificamente humana. Na disciplina arqueológica, artefatos líticos são considerados os principais vestígios materiais de povos caçadorescoletores, e costumam ser analisados de uma maneira clínica, segundo critérios que permitem encaixá-los em esquemas tipológicos. Tal metodologia está intrinsecamente relacionada ao conceito moderno de tecnologia que se caracteriza por sua separação em relação à esfera das relações sociais e da cultura. A partir de uma perspectiva feminista dos estudos tecnológicos, procuro explorar abordagens alternativas para a análise de artefatos líticos, assim como outros enfoques metodológicos possíveis para os estudos de caçadores-coletores, partindo de concepções não modernas de tecnologia.

Palavras-chave: Tecnologia lítica; Crítica feminista; Caçadores-coletores; Teoria arqueológica; Metodologia feminista.

\section{Introdução}

- $m$ meados dos 1980, na esteira do desenvolvimento de arqueologias alternativas, reflexões e reavaliações trazidas principalmente por cientistas mulheres abriram caminho para as análises de gênero no campo da arqueologia, tendo o artigo de Margareth Conkey \& Janet Spector (1984) assentado as bases de um programa explicitamente feminista para a pesquisa arqueológica. No artigo, as autoras chamaram

* Mestre em Antropologia pela Universidade Federal de Pelotas.<danusa.vieiraf@gmail.com> a atenção para o fato de que ao pesquisar elementos da cultura material, padrões de assentamento, relações de parentesco, entre outros, arqueólogos/as trabalhavam com um paradigma em que "as fontes às quais eles recorriam para deduzir suas noções implícitas de arranjos de gênero no passado raramente eram explicitadas" (Conkey \& Spector 1984: 5).

Pesquisadoras feministas destacaram o caráter androcêntrico e etnocêntrico de interpretações arqueológicas relacionadas a papéis e relações de sexo/gênero, assim como da própria prática da disciplina, e como isso se refletia na produção do conhecimento 
(Wylie 2007, 2017). As primeiras pesquisas que continham uma postura crítica ao sexismo e ao androcentrismo na arqueologia comumente se limitavam a apontar o apagamento das mulheres no registro arqueológico, denunciando que o sujeito arqueológico (supostamente) "neutro" se tratava de um homem adulto capaz. Outro ponto levantado por elas era que a maior parte das pesquisas negligenciava mulheres e questões de gênero, mesmo quando estas eram fundamentais para a compreensão do que estava sendo estudado (Wylie 1997).

Também foi objeto da crítica feminista, a forma como mulheres e gênero eram representados quando estes eram considerados, sendo recorrente a naturalização de papéis de gênero e relações domésticas, que, por sua vez, se vale de inferências de gênero ao atribuir funções a artefatos e locais. Além disso, tais variáveis são frequentemente tratadas como aspectos estáveis subjacentes à organização social e vistas como irrelevantes de serem estudadas para se entender contextos de mudança cultural. Dessa maneira, modelos de fenômenos culturais tão diversos, como práticas de subsistência entre caçadorescoletores forrageiros, muitas vezes se transformam na projeção, em povos extintos, de pressuposições "presentistas, etnocêntricas e abertamente androcêntricas sobre divisões sexuais do trabalho e o status e papéis das mulheres" (Wylie 1997: 82).

Neste artigo, tendo em vista a crítica feminista na arqueologia, delineamos como seus questionamentos se colocam em relação aos estudos sobre povos caçadores-coletores em contexto arqueológico trazendo o debate acerca da principal classe de vestígios consideradas nesses estudos, os artefatos líticos, e as concepções de tecnologia subjacentes às metodologias de análise desses objetos. Ao aproximarmos a discussão da noção hegemônica de tecnologia da crítica feminista da ciência, colocamos em questão as premissas das análises tecno-tipológicas que constituem grande parte da produção acadêmica ligada a esse tipo de artefato arqueológico. Em seguida, exploramos brevemente outras maneiras de avaliar a tecnologia e a análise de artefatos de pedra lascada. Por fim, buscamos explicitar as bases e a relevância de se fazer uma pesquisa feminista na arqueologia.

Enquanto um recorte derivado de leituras e reflexões realizadas durante minha pesquisa de mestrado, minhas considerações partem especificamente dos estudos produzidos na arqueologia brasileira sobre os primeiros povos que habitaram as terras baixas da América do Sul na transição do PleistocenoHoloceno para o Holoceno inicial, abrangendo o período cronológico de cerca de 12 mil a 8 mil anos AP.

Embora não seja possível abordar no âmbito deste trabalho, minha pesquisa busca suscitar novas formas de olhar para os vestígios arqueológicos de povos caçadores-coletores extintos, especialmente no contexto brasileiro, explorando os limites epistemológicos e metodológicos de análises morfo-tecno-tipológicas. A partir das epistemologias feministas, procuro apontar na direção de outras abordagens possíveis para a construção de narrativas acerca dos estudos de caçadores-coletores e do povoamento inicial do Brasil.

Sendo uma investigação ainda em curso, mais do que resultados, este artigo tem como objetivo central trazer provocações para o debate acerca dos conceitos de tecnologia e das metodologias de análise de artefatos líticos à luz da perspectiva crítica feminista, ainda muito marginal na arqueologia brasileira.

\section{Crítica feminista e os estudos sobre povos caçadores-coletores}

Povos caçadores-coletores constituem um dos temas mais estudados pela arqueologia. Grande parte desse interesse advém do consenso científico de que a economia forrageira representou o modo de produção mais longevo da espécie humana. Assim sendo, as primeiras populações de humanos e hominídeos viveriam basicamente da coleta 
e da caça ${ }^{1}$, abrindo espaço para uma série de pesquisas que utilizam dados etnográficos, a fim de elaborar analogias arqueológicas entre povos caçadores-coletores atuais e pretéritos, principalmente acerca da organização social, modelo de produção e comportamento desses grupos (Doell \& Longino 1983). Como não poderia ser diferente, esses estudos não escapam do viés masculinista.

Nesse sentido, a obra mais influente foi o livro Man the hunter, editado por Richard Lee \& Irven DeVore (1968), resultante de uma conferência homônima, cujo trabalho abarca um extenso escopo etnográfico, propondo um modelo forrageiro generalizado. Tal modelo encontrou sua sintetização no conceito de "sociedade afluente original", de Marshall Sahlins (2007), e representou o estabelecimento de um paradigma nos estudos antropológicos de sociedades caçadoras-coletoras (Dias 2003).

Daquele compêndio de artigos, se destacam o capítulo "The evolution of hunting" (Washburn \& Lancaster 1968) e também "Hunting: an integrating biobehavior system and its evolutionary importance" (Laughlin 1968) como subsídios clássicos utilizados para elaboração do que ficou conhecido como a perspectiva man-the-hunter ("homem, o caçador").

O modelo man-the-hunter associa a evolução humana ao desenvolvimento da caça (Gaspar, Heilborn \& Escorcio 2011) ao mesmo tempo em que atribui a essa atividade um caráter exclusivamente masculino. Tal hipótese, por sua vez, se baseia numa rígida divisão sexual do trabalho, em que os homens seriam responsáveis pela caça, enquanto as mulheres, pela coleta. Dessa forma, o paradigma man-the-hunter se constitui como um dos modelos teóricos que proclamam a centralidade do desenvolvimento masculino para o desenvolvimento da espécie (Doell \& Longino 1983) e se insere num escopo de teorias antropológicas que sobrevalorizam os homens (Endicott 1999).

A maioria das teorias sobre as primeiras sociedades forrageiras lidam pouco ou quase

1 Há também discussões sobre a possibilidade de se alimentarem de carniça ver Zihlman (2013). nada com a origem da cultura, exceto quando em referência ao advento da caça. $O$ papel idealizado do macho enquanto provedor para uma consorte e sua prole se fundamenta na suposição de que a caça era a técnica mais produtiva e que ela era exercida exclusivamente por homens. Alguns investigadores, assim, veem as atividades cooperativas da caça como essenciais para o desenvolvimento intelectual da espécie (Laughlin 1968), apontando diretamente a atividade de caça como o motor responsável pelo ímpeto de desenvolver instrumentos. Em geral, todas as teorias evolucionistas modernas destacam a caça como o primeiro estágio de desenvolvimento cultural.

Outra suposição do modelo evolucionista man-the-hunter, baseada em observações do comportamento de babuínos², é a constituição da família nuclear como base dos primeiros grupamentos de caçadores-coletores. Segundo esse paradigma, a associação conjugal heteronormativa - seria fundamentada em duas premissas: a da supressão da competição sexual disruptiva entre homens, e a da divisão sexual do trabalho necessária à sobrevivência (Sahlins 1960). Com a união do par homemmulher, essa competição seria neutralizada, permitindo a cooperação necessária entre os homens para as atividades de caça. Por outro lado, tal associação possibilitaria que os homens saíssem para caçar enquanto as mulheres ficariam responsáveis pela coleta e cuidado da prole, atividades que não necessitariam de cooperação. Então, dessa maneira, uma variedade de fenômenos sociais tais quais agressividade masculina inerente (justificada através do comportamento agressivo de machos

2 Pesquisadoras vão questionar a pertinência da comparação com babuínos para estabelecer uma correlação entre esse gênero de primatas e os primeiros grupamentos humanos (ver discussão no capítulo 5 de Martin \& Voorhies 1975). Em seu apoio, pesquisas mais recentes de biologia molecular mostram evidências esmagadoras da proximidade genética entre humanos e chimpanzés em comparação com outros primatas (Bradley 2008). Sendo assim, analogias de comportamento humano com chimpanzés, que são onívoros, habilidosos comunicadores, usam instrumentos, compartilham alimentos, e carregam sua prole por muitos anos, faz muito mais sentido do que a aproximação com babuínos ou uma coleção de comportamentos de diversas espécies (Zihlman 2013), por mais conveniente que isso possa ser 
babuínos $\left.{ }^{3}\right)$, cooperação e ímpeto guerreiro associados a homens, assim como família nuclear e divisão sexual do trabalho, passaram a ser explicados como resultados "naturais" da evolução humana (Zihlman 2013).

Assim, vemos rapidamente estabilizar-se nesse paradigma a argumentação associativa: homem - provedor - caçador - artífice da evolução cultural. Não podemos negar que esse tipo de visão androcêntrica, com homens saindo juntos para caçar animais de grande porte enquanto mulheres ficam em casa para cuidar da prole, lembra perigosamente um padrão de vida de classe média ocidental, onde homens participam da vida pública e mulheres cuidam dos afazeres domésticos (Doell \& Longino 1983), evidenciando a influência de um viés cultural euro-americano.

Tal paradigma androcêntrico do manthe-hunter não demorou a ser duramente criticado. Em contraposição a esse modelo, M. Kay Martin \& Barbara Voorhies (1975) são contundentes em demonstrar, através de um estudo transcultural, que a caça não representa a maior fonte de subsistência para a maioria dos povos caçadores-coletores contemporâneos, e se esforçam em destacar a importância da coleta em todos os grupos analisados. Elas demonstram como o par homem-provedor, mulher-dependente, não se sustenta, tampouco a universalidade da família nuclear (ou conjugal), portanto, nem a caça enquanto uma atividade exclusivamente masculina.

Ademais, vemos um paradoxo no modelo: se há uma rígida divisão sexual do trabalho, e as mulheres são responsáveis pela coleta que representa a maior parte da fonte de subsistência do grupo, como se mantém a visão da mulher improdutiva e dependente? A única saída lógica, nesse caso, seria considerar o trabalho feminino como improdutivo. Eis

3 Ao contrário de babuínos, chimpanzés e gorilas raramente se envolvem em explícitas agressões físicas ou competição sexual por fêmeas no cio. Além disso, pesquisas com chimpanzés mostraram a diversidade de personalidades que podem ser encontradas entre os machos desse gênero primata, e mesmo como as duas espécies desse gênero, Pan paniscus e Pan troglodytes, podem diferir em termos de comportamento masculino (Goodall 1986). mais uma suposição que ecoa do presente a desvalorização do trabalho feminino refletindo mais um aspecto da sociedade moderna capitalista ocidental (Federici 2017).

A partir das discussões sobre os povos caçadoras-coletoras, Frances Dahlberg (1981) edita o livro Woman the gatherer que discute a preponderância da coleta (como contraponto da caça) no modelo de subsistência dos primeiros agrupamentos humanos. Nesse livro, Adrienne Zihlman (1981) discute a maneira como o papel da mulher na evolução humana foi minimizado em estudos evolutivos e comportamentais com primatas. Em outro capítulo, um estudo de caso que se tornou um clássico sobre o assunto, Agnes Estioko-Griffin \& Bion Griffin (1981) trazem o exemplo da sociedade Agta do sudeste asiático em que as mulheres caçam, em pares ou com homens, realizando inclusive o abate de animais de grande e médio porte, sendo ainda responsáveis por trocar a carne obtida por alimentos cultivados por grupos vizinhos agricultores.

Esses e outros estudos ressaltavam a preponderância da mulher no desenvolvimento da espécie, denunciando o viés masculinista nos modelos de organização social proposto para grupamentos humanos já extintos. No entanto, essa perspectiva woman-the-gatherer ("mulher, a coletora”) não logrou se contrapor ao caráter universalizante e transcultural que caracteriza ambos os modelos propostos. Mesmo as/os autoras/es que mais recentemente criticam esse modelo baseado numa visão heteronormativa e depreciativa em relação ao papel da mulher na economia forrageira (Ingold 1999; Endicott 1999) parecem cair na armadilha de não conseguir conceber algo fora da divisão sexual do trabalho.

Um dos efeitos da influência do modelo man-the-hunter, mesmo depois de décadas de crítica feminista, é a associação quase automática entre as atividades de caça e o gênero masculino na literatura arqueológica (Conkey \& Spector 1984; Ribeiro 2017) e antropológica (Endicott 1999) sobre caçadorescoletores. Interessante destacar que Karen Endicott discute em seu artigo como as próprias definições do que é considerado caça 
ou não nos relatos etnológicos variam e como antropólogas/os tendem a dizer que homens "caçam" enquanto mulheres "coletam", mesmo quando os animais capturados são os mesmos (Endicott 1999). Muitas vezes, pesquisas abordando caça e coleta acabam por obliterar as discussões sobre a divisão sexual do trabalho, no lugar de explicitar as premissas que as fundamentam (Schimidt 2018).

Em seu estudo de caso, Doell \& Longino (1983) mostraram diversos problemas metodológicos, especialmente envolvendo a distância entre evidência e hipótese, sendo essa lacuna recorrentemente preenchida por generalizações nada confiáveis e abertamente especulativas acerca do comportamento humano a partir de dados etnográficos de povos caçadores-coletores contemporâneos.

Nessa lógica, por um lado, se o comportamento de coleta feminina for considerado o comportamento crucial de uma adaptação, os artefatos líticos (pedras lascadas) constituem evidência de que as mulheres começaram a desenvolver ferramentas de pedra, além de instrumentos orgânicos já usados para coletar e preparar a vegetação comestível. Por outro lado, se o comportamento da caça masculina é considerado a adaptação crucial, então os artefatos líticos consistem em evidência da invenção masculina de instrumentos para uso na caça e preparação de animais. Portanto, os instrumentos de pedra lascada não podem ser interpretados como sinais inequívocos de um ou outro comportamento específico de uso de ferramentas (Doell \& Longino 1983).

As autoras destacam que, confiando em analogias etnográficas para tentar identificar usos específicos de artefatos líticos, pesquisadoras/es "escorregam" na ausência de um parâmetro universal de sociedades humanas, nem ao menos entre povos caçadorescoletores. Dessa forma, não há como estabelecer padrões gerais de comportamento, e formular, a partir destes, conclusões e paradigmas interpretativos que sirvam para qualquer contexto. Estudos de comportamento entre primatas e pessoas demonstram a natureza inovadora e adaptável da linhagem humana, e se torna até mesmo absurdo pensar que padrões de sociabilidade tenham sido homogêneos ou permanecido inalterados através de milhares, até milhões, de anos.

\section{A importância dos artefatos líticos e as concepções de tecnologia}

Devido, entre outros fatores, ao legado da ênfase excessiva atribuída à caça na tradição man-the-hunter, constituiu-se todo um campo científico dedicado ao estudo daqueles considerados como os principais vestígios materiais de povos caçadores-coletores (Doell \& Longino 1983): os instrumentos líticos - em especial objetos de pedra lascada - e os resíduos de sua produção. Tradicionalmente concebida como a classe de artefato mais bem "preservada" e mais abundante no registro arqueológico (Finlay 2012), os artefatos líticos devem também sua importância a seu papel na compreensão de questões evolutivas. Assim, são considerados "as principais evidências para o entendimento da evolução da humanidade e seus ancestrais”, ou ainda "a melhor evidência para estudo da evolução cultural” (Moreno de Sousa 2018: 35).

Assim sendo, os estudos de tecnologia lítica se relacionam diretamente com o campo científico que trata da evolução humana, principalmente no que concerne a considerações cognitivas e ao comportamento social. Daí decorre a dedução de que os estudos de tecnologia lítica (e suas variações, como estudos morfo-tecno-tipológicos) sejam capazes de fundamentar a verificação de padrões tecnológicos e mudanças culturais, possibilitando interpretar a adaptação de sociedades pretéritas ao meio externo. Como vimos anteriormente, suas inferências em termos de tecnologia são em grande parte construídas com base em analogias etnoarqueológicas produzidas a partir de limitados estudos antropológicos sobre povos caçadores-coletores contemporâneos.

Entretanto, quando tratamos do conceito de tecnologia dentro das ciências, tanto na arqueologia quanto na antropologia, não há consenso. No seu sentido mais fundamental, 
podemos compreendê-la como o estado geral das técnicas. O ensaio seminal de Marcel Mauss (2003) nos coloca o corpo como primeiro e mais básico instrumento humano, sendo as técnicas, assim, essencialmente técnicas do corpo, transmitidas via tradição. Em uma concepção mais ampla, podemos entendê-la como "o conjunto de artefatos, comportamentos e conhecimentos empregados pelo homem na transformação e utilização do mundo material" (Silva 2000: 21), onde apenas substituiremos "homem" por "pessoa humana". Sendo o mundo material objeto de estudo próprio da arqueologia, podemos então entender como o estudo da tecnologia se tornou hegemônico na ciência social arqueológica moderna.

Para além do foco no estudo dos próprios objetos e suas configurações tipológicas de inspiração histórico-culturalista, que dominou boa parte da produção arqueológica e ainda está longe de ser abandonado, os estudos tecnológicos se inserem na perspectiva de compreender melhor os processos de produção relativos à cultura material. Nesse sentido, a visão da cultura como um meio extrassomático de adaptação humana ao ambiente de Leslie White (1959) moldou a principal forma, na arqueologia, de se enxergar a tecnologia. Entendendo a cultura material como um mediador entre o sistema sociocultural e o meio ambiente, para autoras/es adeptos dessa concepção, influenciados pelo pensamento neoevolucionista e da ecologia cultural, seria possivel perceber as estratégias adaptativas através da análise de artefatos - produtos do comportamento humano.

Numa outra perspectiva, procurando inserir a tecnologia no sistema cultural e sua teia de significados que não se limitam à esfera econômica ou da adaptabilidade (Silva 2000), entende-se que os artefatos fazem parte de sistemas tecnológicos que se articulam com sistemas socioculturais humanos. Essa noção teórica de tecnologia foi inspirada em autores como Mauss, Leroi-Gourhan e Lévi-Strauss, e contribuiu para a constituição do que ficou conhecido como "antropologia da tecnologia" (Lemonnier 1993).
Um importante autor desse campo, Tim Ingold $(1997,2000)$ procura trazer reflexões que nos ajudam a pensar mais profundamente como se dá essa relação entre tecnologia e sociedade. $\mathrm{Na}$ base das indagações suscitadas pelos estudos tecnológicos estão envolvidas questões acerca do que nos torna especificamente humanos, ou dito de outra forma, as capacidades que distinguiriam seres humanos de animais não humanos. A própria constituição do que caracteriza o gênero humano enquanto espécie em estudos paleoantropológicos está intimamente relacionada à nossa capacidade de fabricar instrumentos de forma intencional - a difundida noção do man-the-toolmaker ("homem, o fabricante de instrumentos"), intimamente relacionada à visão de mundo que deu origem ao modelo man-the-hunter. Os estudos tecnológicos também estão imbricados nas pesquisas sobre evolução humana, sobretudo a evolução da linguagem, que teria paralelos com o desenvolvimento da cultura material.

Para Ingold (1997), existem duas formas majoritárias e distintas para perceber a relação entre tecnologia e sociedade, o determinismo tecnológico e o possibilismo tecnológico, conjuntos de argumentações usadas por evolucionistas culturais, de um lado, e relativistas culturais, de outro. Para as/os evolucionistas culturais, a tecnologia possuiria uma tendência inerente de se desenvolver do simples para o complexo ${ }^{4}$. Dessa maneira, as formas associadas de organização social e cultura igualmente tenderiam à complexificação, conduzidas pelas exigências tecnológicas subjacentes. Sendo assim, a mudança social seria conduzida pela - e dependeria da mudança tecnológica. Já as/os relativistas negam qualquer relação entre complexidade social e complexidade tecnológica, demarcando a tecnologia apenas em limites externos ao escopo de ação humana, sem exercer influência na forma de sociedade adotada. Dentro desse limites, sociedade e cultura

4 O que não é o caso dos evolucionistas darwinianos, que entendem evolução como transformação, ou o processo de substituição de uma forma por outra, sem indicativo de progresso. 
seguiriam seu próprio fluxo histórico, independentemente da natureza ou complexidade do sistema tecnológico. Para isso, resgatam exemplos etnográficos em que sociedades com tecnologias consideradas extremamente simples, ostentam sistemas de parentesco dos mais complexos já registrados, como os aborígenes australianos (Ingold 1997).

Apesar de terem concepções que aparentam ser diametralmente opostas, há duas suposições que são compartilhadas por ambas as correntes. Uma delas é que, sendo a tecnologia prescritiva ou permissiva no que diz respeito à sociedade, ela consistiria em um sistema objetivo de relações que se situaria fora do domínio do social. A segunda é de que a tecnologia poderia de fato ser dimensionada em termos de graus de complexidade. Ambas as visões compartilham a premissa que toda população humana teria uma esfera de capacidade que pode ser denotada pelo conceito de tecnologia, e que poderia ser separada da esfera das relações sociais e das ideias culturais. Dessa maneira, a tecnologia foi posta por pesquisadoras/es fora do social e do âmbito da cultura.

Ingold argumenta, porém, que essa seria uma pressuposição equivocada, já que tecnologia e sociedade não são intrinsecamente exteriores um ao outro. Essa exterioridade, longe de ser algo inerente, seria um produto histórico relativamente recente, emergido na modernidade ocidental. Nesse sentido, Ingold faz coro com a perspectiva feminista ao afirmar que não é possível projetar na história essa separação moderna entre tecnologia e sociedade, estendendo-a a todas as sociedades humanas, sem distorcer seriamente nossa compreensão sobre o fenômeno. Tal fragmentação entre tecnologia e sociedade faz sentido dentro de um escopo epistemológico moderno e positivista onde é factível separar o sistema sociocultural em subsistemas (Binford 1962).

Ao contrário do pensamento dominante na arqueologia, Ingold $(1997,2000)$ concebe as relações tecnológicas como estando incorporadas nas relações sociais e só podendo ser compreendidas enquanto um dos aspectos da socialidade humana. Nessa linha, o que geralmente é representado como processo de complexificação - de desenvolvimento do simples para o complexo -, se trata, na realidade, do processo de exteriorização ou dissociação, da separação progressiva entre as relações tecnológicas e as sociais. Dessa maneira, o conceito moderno de tecnologia, e sua separação da sociedade, seria uma consequência direta desse processo histórico. Por isso, não seria plausível esperar encontrar uma esfera separada correspondente à "tecnologia" para onde quer que olhemos, sobretudo em sociedades onde não houve esse processo dissociativo, como as sociedades caçadoras-coletoras extintas.

Nesse sentido, as reflexões levantadas por Ingold reverberam as de Lemonnier (1993) quando este se indaga se seria possível interpretar as mudanças e as escolhas tecnológicas de cada sociedade desconsiderando outros aspectos da cultura. Mesmo este último reconhece que

logo que consideramos que as técnicas não são algo ao qual algum significado é simplesmente adicionado, mas um fenômeno complexo em que considerações simbólicas estão envolvidas desde o começo, se torna complicado de separar o 'técnico' do 'social' (ou, ainda, o 'social-além-do-técnico') (Lemonnier 1993: 4).

Ainda, para Lemonnier (1993), dependendo do ponto de vista do observador, a fronteira entre os fenômenos "técnico" e "social" podem trocar de posição. Assim, se uma técnica aplicada pode nos parecer um meio de atingir um objetivo físico a partir de meios materiais, num processo criativo de inovação, esses mesmos elementos "técnicos" foram provavelmente escolhidos majoritariamente de acordo com estratégias e significados socialmente compartilhados.

O esforço reflexivo empreendido por Ingold, entretanto, não é de todo inédito, sendo análogo ao empenho de antropólogas/ os em demonstrar que economia e sociedade foram institucionalmente separadas no curso de desenvolvimento do capitalismo ocidental. Nessa lógica, em sociedades não capitalistas, 
as relações econômicas não estariam dissociadas, mas embutidas, entrelaçadas nas relações sociais.

$\mathrm{Na}$ disciplina arqueológica clássica, objetos, principalmente artefatos líticos, são analisados de uma maneira clínica, mensurados, desenhados, pesados, segundo critérios que os permitem ser encaixados em esquemas tipológicos, e encaixados em quadros analíticos (Laming-Emperaire 2017) para posteriormente serem interpretados. Normas de validade para estudos tecnológicos costumam pressupor ao menos algum aspecto tecno-tipológico incorporado à análise (Cobb 2006).

No Brasil, os manuais de referência para o estudo de tecnologia lítica e de tecnologia da pedra lascada (Inizan et al. 2017; LamingEmperaire 2017; Prous 1986/1990), em acordo com os princípios tecnológicos positivistas que os norteiam, pressupõem a universalidade inerente à produção tecnológica humana, principalmente quanto à utilização dos objetos de pedra, que goza de "uma classificação, que nos parece apresentar a vantagem de corresponder, não a determinadas regiões ou culturas, mas a necessidades universais do Homo-faber" (Laming-Emperaire 2017: 20). Esses guias, assim, subvalorizam referências analógicas locais - etnográficas, etno-históricas na produção de tipologias classificatórias de artefatos, priorizando definições transculturais já consolidadas, em sua maioria elaboradas tendo como base instrumentos líticos do Paleolítico e Neolítico europeus, ou do Oriente Próximo.

Há uma tentativa explícita, no entanto, de se adequar as tipologias ao contexto sulamericano, especialmente nos manuais de Annete Laming-Emperaire e de André Prous, trazendo inclusive classificações sem correspondentes nos manuais europeus (por exemplo, "quebra-coquinhos"). Porém, poucas são as referências locais e etnográficas, sendo estas últimas ausentes no guia de Annette Laming-Emperaire.

Nos estudos sobre povos caçadores-coletores extintos, no que corresponde ao atual território brasileiro, predominam os artefatos líticos lascados como linhas de evidência - sobretudo artefatos formais, como instrumentos bifaciais. Além disso, eles se caracterizam pela ênfase nas análises de cunho tecnológico, e, mais recentemente, com recurso à arqueologia experimental, o que pode ser visto como uma influência da Nova Arqueologia, não só no país, mas enquanto tendência mundial.

\section{Sobre técnicas e tecnologia: uma crítica feminista}

A maneira universalista e

descontextualizada que a tecnologia é abordada nos estudos sobre caçadores-coletores pretéritos, e os instrumentos líticos a eles atribuídos, parte de um princípio de objetividade neutra fundante da concepção de ciência moderna. Nessa concepção de objetividade, o sujeito do cientista desinteressado seria condição sine qua non para a produção de um conhecimento confiável, e por sua vez, esta seria uma exigência para o desenvolvimento de uma "boa ciência".

Helen Longino (1987) destaca a força da percepção dominante de ciência em que a metodologia científica sozinha seria capaz de garantir a independência da investigação, engendrando uma ciência intrinsecamente desprovida de valores. Dessa maneira, a "boa ciência” é aquela livre de valores, enquanto uma ciência orientada por valores é vista como "má ciência" (Longino 1987: 53). Essa ideia tem base numa concepção abstrata e individualista, de uma separação clara entre valores cognitivos e não cognitivos (sociais), onde os primeiros seriam caracterizados por fundamentos universais de racionalidade. Temos então um entendimento a-perspectivo da objetividade da "boa ciência" que paira acima de quaisquer interesses ou valores situados, onde o conhecimento objetivo só pode ser realizado se agentes epistêmicos forem capazes de superar aspectos contextuais (Wylie apud Koide, Ferreira \& Marini 2014).

Trazer a crítica feminista dessa suposta "visão a partir de lugar nenhum" (Wylie apud Koide, Ferreira \& Marini 2014: 574) é importante para a compreensão de que o 
conhecimento não se produz num vácuo. Vieses ocidentais e androcêntricos (entre outros) se imiscuem na elaboração de teorias e hipóteses, por mais rigorosos que sejam os procedimentos metodológicos adotados de acordo com as normas disciplinares vigentes dentro de um campo científico.

Isso porque fazer uma pesquisa feminista não implica considerar "gênero" de antemão como uma categoria pertinente para qualquer análise, mas sim "fazer ciência como feminista" (Longino 1987: 53), ou seja, ter sempre em mente as bases androcêntricas nas quais se alicerça a prática científica moderna. Significa, assim, reconhecer que a prática científica apresenta disparidades que refletem

\section{o modelo padrão para caracterizar} aqueles em posições subdominantes. Assim, o que significa ser uma mulher, um sujeito colonizado, em suma, um membro de uma classe subordinada, é simplesmente ser: não homem, não branco, não membro de uma elite colonial (Wylie apud Koide, Ferreira \& Marini 2014: 567).

Assim, realizar uma crítica feminista também pressupõe uma abordagem engajada que vá além da categoria "mulher" e leve em conta outros tipos de opressões operando na construção do conhecimento, como raça, etnicidade e classe (Blackmore 2011; Davis 2016).

Nessa concepção, a teoria feminista do "ponto de vista" (Wylie 2017) nos ajuda a pensar essas questões na medida em que entendemos que todo saber é localizado (Haraway 1995) e todo conhecimento científico é situado no contexto históricoparticular de um "lugar" em que as várias experiências de opressão, como gênero, raça, classe e sexualidade, são produzidas historicamente (Davis 2016). A teoria feminista do ponto de vista parte de uma concepção de objetividade, não calcada na neutralidade dos sujeitos e sujeitas que fabricam conhecimento, mas fundamentada em estratégias de maximização da objetividade, por meio de agentes epistêmicos reflexivos, localizados, especialmente os insiders-outsiders, [que] frequentemente levam considerável vantagem quando se trata de reconhecer a influência e as limitações do sistema de referência de pressupostos que os marcam como outsiders, mas que os insiders podem considerar natural (Wylie 2017: 30).

Alison Wylie defende a mobilização de recursos de membros de fora da comunidade cientifica, os outsiders, pois estes se encontram numa posição "privilegiada" no sentido de trazer uma perspectiva crítica a normas disciplinares de determinado campo científico. Em outras palavras, consiste no entendimento de que "quem está de fora" é capaz de observar melhor as desigualdades dentro de um campo científico, trazendo à tona críticas e práticas transformadoras. Nessa mesma lógica, Sandra Harding (1995) defende que a teoria do ponto de vista fortaleceria a strong objectivity (objetividade forte), que funcionaria com mais eficácia do que a (tradicional) objetividade neutra com relação a áreas de pesquisa mais suscetíveis de serem moldadas por valores e interesses dos mais poderosos (Harding 1995).

Partindo dessas bases, é possível questionar o modo como certos enfoques de análise formal de artefatos podem ser privilegiados (quais perguntas são feitas, quais atributos serão destacados), assim como as interpretações decorrentes de tais opções metodológicas. A seleção dos tipos de artefatos a serem analisados pode priorizar parâmetros e modelos previamente estabelecidos também. Por exemplo, o foco analítico em evidências supostamente ligadas à caça (Wylie 1997) como artefatos formais, sobretudo pontas de projétil, pode ser observado em um grande número de trabalhos sobre o período de povoamento inicial da América do Sul (12 mil a 9 mil AP).

Dessa forma, entendo que a prática arqueológica pode se beneficiar de um empiricismo contextual, assim como de propostas epistêmicas estabelecidas localmente, e de conhecimentos que partem de um ponto de vista de outsiders e outsiders-insiders. Logo, este trabalho 
busca refletir acerca da hegemonia de metodologias positivistas-universalistas de análise, suscitando indagações acerca de como parâmetros calcados em modelos transculturais e universalistas podem ter distorcido ou limitado nosso entendimento sobre povos caçadores-coletores.

Nessa linha, há algumas abordagens metodológicas que se mostram bastante promissoras em apresentar alternativas ao enfoque clássico de análise tecnológica de artefatos líticos. Entre elas, está uma maneira inovadora de abordar a etnoarqueologia para compreender de que forma a confecção de instrumentos de pedra lascada se insere na complexidade das relações sociais, e como isso se dá em contextos sociais específicos (Arthur 2010, 2018). Ademais, é possível explorar a relação desses artefatos com questões ontológicas, que nos ajudem a desenvolver um tipo de conhecimento menos descritivo e mais interpretativo, sem ter que apelar para analogias universais e descontextualizadas.

A pesquisadora Kathryn Weedman Arthur, em sua obra The lives of stone tools (2018), nos mostra como o ciclo de vida de um instrumento lítico na sociedade dos Boreda Gamo da Etiópia, uma etnia que tradicionalmente trabalha o couro com artefatos de pedra lascada, está intimamente ligado aos estágios de vida de seres humanos. Sendo assim,

na ontologia Boreda, um instrumento de pedra é uma entidade viva que nasce quando adquirido, é circuncidado quando lascado, descansa quando armazenado, se casa quando encabado, é ativo quando usado, e morto quando descartado (Arthur 2018: 65).

De acordo com sua ontologia, Etta Woga, a tecnologia da fabricação de artefatos de pedra lascada está simbolicamente ligada à fertilidade e às mulheres, porque são elas que fazem o "nascimento" da rocha a ser lascada, respeitando sua prerrogativa enquanto parteiras dentro de seu entendimento cosmológico.

Não deixa de ser impressionante, nesse caso, a completa subversão da ideia de que mulheres apenas utilizavam, mas não produziam seus próprios instrumentos de pedra lascada no passado. Além da tecnologia de produção de instrumentos de pedra lascada estar intimamente ligada ao feminino, a própria aquisição de matériasprimas também não pode ser descolada de sua perspectiva ontológica, já que procuram buscá-las perto de árvores e da água, simbolizando lugares de mudança e transformação.

Nesse sentido, a construção de modelos sobre a aquisição de matéria-prima de grupos caçadores-coletores, que consideram aspectos estritamente utilitaristas, corre o risco de projetar valores ocidentais em povos que não compartilham absolutamente dessa concepção de mundo. Assim, apartar a tecnologia do âmbito das relações sociais, na melhor das hipóteses, pode acabar gerando uma ficção científica que apresenta severas limitações para a compreensão de como viviam as pessoas que estudamos no passado. Como bem aponta Kathryn W. Arthur (2018), é imperativo entender que ontologias indígenas são, por si só, teorias da realidade válidas para explicar como humanos e artefatos existem e interagem, e não precisam ser reformuladas ou apropriadas.

Precisamos incentivar a decolonização da ciência e da história, e estar abertas/os para acolher os conhecimentos de povos originários como legítimos e incontornáveis, resistindo ao ímpeto de reescrever ontologias indígenas de acordo com tradições teóricas ocidentais e apenas utilizá-las para ilustrar o aspecto "simbólico" de determinado artefato ou prática social.

Outra perspectiva potencialmente congruente à ótica feminista consiste tanto em considerar a múltipla autoria de instrumentos líticos quanto o caráter comunal e recíproco de sua produção e uso, fato destacado em diversos relatos etnográficos, e amplamente desconsiderado na construção de modelos de análise de tecnologia lítica (Finlay 2012). Quando há uma série de peças "mal trabalhadas" numa coleção de artefatos líticos, explicações tradicionais discorrem 
sobre restrições de matéria-prima (acesso apenas a matérias-primas de baixa qualidade) ou consideram se tratar de instrumentos expedientes, raramente aludindo a diferentes níveis de habilidade.

É recorrente que tais artefatos escapem às tipologias, sendo consideradas peças anômalas, e não ganhem maior atenção.

Na prática, elas podem ser uma excelente fonte de informações para destrinchar a

"vida" de determinado artefato, abrindo caminhos para enxergar intervenções de diferentes sujeitas/os num mesmo objeto, assim como permitem vislumbrar questões mais amplas de sociabilidade.

Isso porque há diversos indícios de artefatos sendo retrabalhados por pessoas com níveis de habilidade diferentes. Núcleos previamente utilizados por lascadoras/es experientes para confeccionar instrumentos são retrabalhados por pessoas menos competentes, como crianças, aprendizes, ou pessoas cuja habilidade motora e/ou a visão podem estar prejudicadas pela idade (pessoas idosas) ou por alguma condição temporária (Finlay 2012; Arthur 2010). Isso vai contra uma concepção ocidental-individualista de produção dos artefatos, alterando nossa percepção sobre sua análise.

Outra linha importante, seria colocar em questão a ênfase de estudos em artefatos formais, considerados complexos, em detrimento da análise de instrumentos considerados mais simples, como acontece na arqueologia de povos caçadores-coletores no Brasil. Ainda por influência do modelo man-the-hunter, essa tecnologia mais "simples" costuma ser associada a mulheres e atividades outras que não a caça, tendo sua capacidade analítica subestimada (Finlay 2006; Gero 1991).

Quando tratamos especificamente dos primeiros povos a habitarem o território brasileiro no período da transição do Pleistoceno-Holoceno para o Holoceno inicial, são diversos os modelos de povoamento elaborados para elucidar considerações quanto a seu modo de vida, mobilidade, subsistência, entre outras ${ }^{5}$. Nesses modelos, a formulação de hipóteses se fundamenta prioritariamente na dispersão espacial de complexos tecnológicos de pedra lascada para pensar rotas de migração populacional. Partindo de uma ótica feminista, seria preciso olhar para além de vestígios reiteradamente associados a povos caçadorescoletores, através da incorporação de outras/ os sujeitas/os e discursos na Arqueologia, ou até mesmo olhando para outra classe de dados ainda subestudados, como os vestígios vegetais. Nesse sentido, a antracologia e a arqueobotânica podem ser de enorme valia para entender como povos utilizavam e significavam as plantas e árvores que os cercavam.

Não raro ouvimos o clássico argumento do caráter limitante do registro arqueológico, em que vestígios orgânicos raramente se preservam e, portanto, a principal justificativa para a primazia da análise lítica em contextos muito antigos seria a abundância de artefatos em pedra lascada nesse tipo de sítio arqueológico. Entretanto, ao longo deste texto, mostramos como a preponderância de estudos líticos não remete a meros impasses e impossibilidades metodológicas, mas corresponde ao estabelecimento de uma agenda de pesquisa que prioriza certa classe de registro, construindo hipóteses e modelos em conformidade com uma epistemologia ocidental e sexista.

\section{Considerações Finais}

Neste artigo, procurei delinear caminhos viáveis a serem trilhados na direção de metodologias que possam inspirar abordagens feministas, localizadas e contra-hegemônicas no âmbito dos estudos sobre os primeiros povos que aqui habitaram. Longe de esgotar o assunto, o presente trabalho busca, sobretudo, fomentar discussões e contribuir para um outro olhar em relação a esse tema.

Por fim, como vimos, a pesquisa feminista baseada na teoria do ponto de vista supõe

5 Para uma perspectiva ampla sobre esse tema, ver o dossiê "Cenários e Processos das Primeiras Ocupações do Brasil: O Papel da Pesquisa Arqueológica” (Boletim do Museu Paraense Emílio Goeldi. Ciências Humanas 2019). 
assumir uma posição de identificação com sujeitas/os que de algum modo não se colocam como favorecidos pelas normas epistêmicas dominantes nas estruturas de produção de conhecimento. Importante frisar que, quando parto de uma perspectiva feminista, não estou presumindo que "mulheres" no passado distante com o qual estou lidando ocupam esse lugar de sujeitas exploradas/oprimidas/espoliadas.
A coerência de minha pesquisa, portanto, está ancorada na crítica às representações arqueológicas dominantes sobre sociedades caçadoras-coletoras pretéritas. Tais interpretações, por meio da projeção de concepções presentistas de modos de vida, reproduzem vieses sexistas, racistas, classistas e heteronormativos em suas narrativas, assim reforçando e legitimando desigualdades e opressões no presente.

VIEIRA, D. About techniques and technology: a feminist perspective of lithic artifacts studies. R. Museu Arq. Etn., 36: 95-108, 2021.

\begin{abstract}
Substantial theoretical reflections have been made about technology as a means of action in the physical, social and culturally constituted world, including considerations that derive from the material aspect of the social production of techniques, as well as inventions considered crucial for human evolution. Chipped stone artifacts fall into this fundamental category, constituting a specifically human intentional technical production. In the archaeological field, lithic artifacts are considered the main material traces of hunter-gatherer peoples, and they are typically analyzed in a clinical manner following typological criteria. Such methodology is intrinsically related to the modern concept of technology which is characterized by its separation from the sphere of social relations and culture. From a feminist perspective of technological studies, I explore alternative approaches to the analysis of lithic artifacts, as well as another possible methodological focus for hunter-gatherer studies based on non-modern conceptions of technology.
\end{abstract}

Keywords: Lithic technology; Feminist critique; Hunter-Gatherers; Archaeological theory; Feminist methodology.

\title{
Referências Bibliográficas
}

Arthur, K.W. 2010. Feminine knowledge and skill reconsidered: women and flaked stone tools. American Anthropologist 112: 228-243.

Arthur, K.W. 2018. The lives of stone tools: crafting the status, skill, and identity of Flintknappers. University of Arizona Press, Tucson.

Binford, L. 1962. Archaeology as Anthropology. American Antiquity 28: 217-225.
Blackmore, C. 2011. How to queer the past without sex: queer theory, feminisms and the archaeology of identity. Archaeologies 7: 75-96.

Boletim do Museu Paraense Emílio Goeldi. Ciências Humanas. 2019. 14: 259-676.

Bradley, B.J. 2008. Reconstructing phylogenies and phenotypes: a molecular view of human evolution. Journal of Anatomy 212: 337-353. 
Cobb, H. 2006. (Dead) Bodies the matter? Examining prehistory from a queer perspective. In: Anais da UK Postgraduate Conference in Gender Studies, 2006, Leeds. Disponível em: <https://bit. ly/37gZiZA>. Acesso em: 31/07/2020.

Conkey, M.; Spector, J. 1984. Archaeology and the study of gender. Advances in Archaeological Method and Theory 7: 1-38.

Dahlberg, F. (Ed.). 1981. Woman the gatherer. Yale University Press, New Haven.

Davis, A. 2016. Mulheres, raça e classe. Boitempo, São Paulo.

Dias, A.S. 2003. Sistemas de assentamento e estilo tecnológico: uma proposta interpretativa para a ocupação pré-colonial do alto vale do rio dos sinos, Rio Grande do Sul. Tese de doutorado. Museu de Arqueologia e Etnologia da Universidade de São Paulo, São Paulo.

Doell, R.; Longino, H. 1983. Body, bias, and behavior: a comparative analysis of reasoning in two areas of biological science. Signs 9: 206-227.

Endicott, K. 1999. Gender relations in hunter-gatherer societies. In: Lee, R.; Daly, R. (Ed.).

The Cambridge encyclopedia of hunters and gatherers. Cambridge University Press, Cambridge; New York, 411-418.

Estioko-Griffin, A.; Griffin, P. B. 1981. Woman the hunter: the Agta. In: Dahlberg, F. (Ed.). Woman the gatherer. Yale University Press, New Haven, 121-152.

Federici, S. 2017. Calibã e a bruxa: mulheres, corpo e acumulação primitiva. Elefante, São Paulo.

Finlay, N. 2006. Manifesting microliths: insights and strategies from experimental replication. In: Anais do Symposium Skilled production and social reproduction: aspects of traditional stone tool technologies, 2003, Uppsala, 299-314.

Finlay, N. 2012. Gender and lithic studies in prehistoric archaeology. In: Bolger, D. (Ed.).
A companion to gender prehistory.

Wiley-Blackwell, Malden, 142-160.

Gaspar, M.D.; Heilborn, M.L.; Escorcio, E. 2011. A sociedade sambaquieira vista através de sexo e gênero. Revista do Museu de Arqueologia e Etnologia 21: 17-30.

Gero, J. 1991. Genderlithics: women's roles in stone tool production. In: Conkey, M.; Gero, J. (Eds.). Engendering archaeology: women and prehistory. Blackwell Publishing, Oxford, 163-193.

Goodall, J. 1986. The chimpanzees of Gombe. Harvard University Press, Cambridge.

Haraway, D. 1995. Saberes localizados: a questão da ciência para o feminismo e o privilégio da perspectiva parcial. Cadernos Pagu 5: 7-41.

Harding, S. 1995. "Strong objectivity": a response to the new objectivity question. Synthese 104: 331-349.

Ingold, T. 1997. Eight themes in the anthropology of technology. Social Analysis 41: 106-138.

Ingold, T. 1999. On the social relations of the hunter-gatherer band. In: Lee, R.; Daly, R. (Eds.). The Cambridge encyclopedia of hunters and gatherers. Cambridge University Press, Cambridge; New York, 399-410.

Ingold, T. 2000. The perception of the environment: essays on livelihood, dwelling and skill. Routledge, London.

Inizan, M.-L.; Reduron-Ballinger, M.; Roche, H.; et al. 2017. Tecnologia da pedra lascada. MHNJB-UFMG, Belo Horizonte.

Koide, K.; Ferreira, M.; Marini, M. 2014. Arqueologia e a crítica feminista da ciência: entrevista com Alison Wylie. Scientiae Studia 12: 549-590.

Laming-Emperaire, A. 2017. Guia para o estudo das indústrias líticas da América do Sul. CEPA, Curitiba. 
Laughlin, W. 1968. Hunting: an integrating biobehavior system and its evolutionary importance. In: Lee, R.; DeVore, I. (Eds.). Man the hunter. Aldine, Chicago, 304-320.

Lee, R.; DeVore, I. (Eds.). 1968. Man the hunter. Aldine, Chicago.

Lemmonier, P. 1993. Introduction. In: Lemonnier, P. (Ed.). Technological choices. Routledge, London.

Longino, H. 1987. Can there be a feminist science? Hypatia 2: 51-64.

Martin, M.K.; Voorhies, B. 1975. Female of the species. Columbia University Press, New York.

Mauss, M. 2003. As técnicas do corpo. In: Mauss, M. Sociologia e antropologia. Cosac Naify, São Paulo, 399-422.

Moreno de Sousa, J.C. 2018. Tecnologia de Ponta a Ponta: Em busca de mudanças culturais durante o holoceno em indústrias líticas do sudeste e sul do Brasil. Tese de doutorado. Universidade Federal do Rio de Janeiro, Rio de Janeiro.

Prous, A. 1986-1990. Os artefatos líticos, elementos descritivos classificatórios. Arquivos do Museu de História Natural 11: 1-55.

Ribeiro, L. 2017. Crítica feminista, arqueologia e descolonialidade. Revista de Arqueologia 30: $210-234$.

Sahlins, M. 1960. The origin of society. Scientific American 203: 76-87.

Sahlins, M. 2007. A sociedade afluente original. In: Sahlins, M. Cultura na prática. Editora UFRJ, Rio de Janeiro, 105-152.
Schimidt, S.K. 2018. Garimpeiras locais contra as Minas Gerais: o que elas me ensinaram sobre Capitalismo e Ciência. Dissertação de mestrado. Universidade Federal de Pelotas, Pelotas.

Silva, F. 2000. As Tecnologias e seus Significados: um estudo da cerâmica dos Asuriní do Xingu e da cestaria dos Kayapó-Xikrin sob uma perspectiva etnoarqueológica. Tese de doutorado. Universidade de São Paulo, São Paulo.

Washburn, S.; Lancaster, C. 1968. The evolution of hunting. In: Lee, R.; DeVore, I. (Eds.). Man the hunter. Aldine, Chicago, 293-303.

White, L. 1959. The evolution of culture: the development of civilization to the fall of Rome. McGraw-Hill, New York.

Wylie, A. 1997. The engendering of archaeology refiguring feminist science studies. Osiris 12: 80-99.

Wylie, A. 2007. Doing archaeology as a feminist: introduction. Journal of Archaeological Method and Theory 14: 209-216.

Wylie, A. 2017. Os que conhecem, conhecem bem: teoria do ponto de vista e arqueologia de gênero. Scientiae Studia 15: 13-38.

Zihlman, A. 1981. Women as shapers of the human adaptation. In: Dahlberg, F. (Ed.). Woman the gatherer. Yale University Press, New Haven, 75-120.

Zihlman, A. 2013. Engendering human evolution. In: Bolger, D. (Ed.). A companion to gender prehistory. Wiley-Blackwell, Malden, 23-44. 